Oosterveld-Vlug, M., Oldenkamp, M., Mastebroek, M. What difficulties do people with mild intellectual disabilities experience when seeking medical help from their GP? A qualitative study. Journal of Applied Research in Intellectual Disabilities: 2020, 34(1), p. 178-189

$\begin{array}{lll}\text { Postprint version } & : & 1.0 \\ \text { Journal website } & : & \text { https://onlinelibrary.wiley.com/doi/abs/10.1111/jar.12796 } \\ \text { Pubmed link } & : & \text { https://pubmed.ncbi.nlm.nih.gov/32924273/ } \\ \text { DOI } & : & 10.1111 / j a r .12796\end{array}$

This is a Nivel certified Post Print, more info at nivel.nl

\title{
What difficulties do people with mild intellectual disabilities experience when seeking medical help from their GP? A qualitative study
}

\author{
Mariska Oosterveld-Vlug ${ }^{1}$, Marloes Oldenkamp ${ }^{1}$, Mathilde Mastebroek ${ }^{2}$, \\ Hennie Boeije ${ }^{1}$
}

1. Nivel, Netherlands Institute for Health Services Research, Utrecht, The Netherlands

2. Department of Primary and Community Care, Radboud University Medical Centre, Nijmegen, The Netherlands

\begin{abstract}
Background: People with intellectual disabilities often have low health literacy as a result of their limited language comprehension. The aim of this study was to explore the difficulties Dutch people with intellectual disabilities experience during the process of considering and seeking medical help from their GP. The study was intended as input for an online intervention supporting health literacy.

Methods: A qualitative study, in which 12 semi-structured interviews were conducted with people with mild intellectual disabilities and 4 with relatives of people with mild intellectual disabilities. The interviews were analysed following the principles of thematic analysis.

Results: Difficulties were experienced in the following activities: assessing and proactively reacting to health complaints, processing health information, communicating with a GP and retaining information from the consultation. Support workers and relatives play an important role in all these activities.

Conclusions: To increase the capacity of people with intellectual disabilities to manage their health and seek care from their GP, it is important to support them in the activities they find difficult. Recommendations resulting from the study have been incorporated in an online intervention.
\end{abstract}

\section{Introduction}

Citizens in the Netherlands and other Western countries have increasingly been expected to fulfil an autonomous and responsible role when it comes to their health and health care. People with intellectual disabilities too are expected to manage their own health and be as self-reliant as 
Oosterveld-Vlug, M., Oldenkamp, M., Mastebroek, M. What difficulties do people with mild intellectual disabilities experience when seeking medical help from their GP? A qualitative study. Journal of Applied Research in Intellectual Disabilities: 2020, 34(1), p. 178-189

possible. Due to shifts in the care system and societal changes (Vilans, 2020), they are now more likely to live independently with floating support from an intellectual disabilities service care provider several hours a day or a week, and are more likely to receive care from a general practitioner (GP) as their principal physician instead of specialized physicians in intellectual disabilities care settings (see Box 1). Managing one's own health can be quite challenging for people with intellectual disabilities, especially considering the fact that they experience more health problems than the general population and more challenges accessing the appropriate health services (Einfeld et al., 2006; Ouellette-Kuntz, 2005; Straetmans, van Schrojenstein Lantman - de Valk, Schellevis, \& Dinant, 2007).

An important determinant that contributes to these health inequalities is that people with intellectual disabilities often have low health literacy (Engels, Wijenberg, \& Schepers, 2015; Krahn, Hammond, \& Turner, 2006; Mastebroek, Naaldenberg, Lagro-Janssen, \& van Schrojenstein Lantman de Valk, 2014; Ouellette-Kuntz, 2005; Webb \& Stanton, 2008). The term health literacy refers to "the degree to which individuals can obtain, process, understand, and communicate about health-related information needed to make informed health decisions" (Berkman, Davis, \& McCormack, 2010). Osborne, Batterham, Elsworth, Hawkins, and Buchbinder (2013) defined nine domains of health literacy, referring to a person's cognitive, psychological and social abilities and needs. These are as follows: 1 . Ability to find good health information; 2 . Appraisal of health information; 3 . Social support for health; 4. Actively managing own health; 5 . Feeling understood and supported by healthcare providers; 6 . Having sufficient information to manage own health; 7 . Ability to actively engage with healthcare providers; 8. Navigating the healthcare system; and 9. Understand health information well enough to know what to do. People with low health literacy, including people with intellectual disabilities, have problems with reading and understanding health-related information, recognizing health problems and communicating with caregivers, which could possibly lead to a wrong interpretation of health complaints and seeking medical aid untimely and inadequately. This might eventually cause aggravation of complaints, reduced quality of life and increased healthcare use (Berkman, Sheridan, Donahue, Halpern, \& Crotty, 2011; Mastebroek et al., 2014; Paasche-Orlow \& Wolf, 2007).

Health literacy skills can be enhanced with the right form of support (Berkman, Sheridan, Donahue, Halpern, Viera, et al., 2011; Rademakers, 2014). In the eHealth era we live in, an online intervention seems a suitable way to do this (Kim \& Xie, 2017), including for people with intellectual disabilities whose Internet usage patterns are quite comparable to people without disabilities (Jenaro et al., 2018). However, at present, limited knowledge is available about the difficulties people with intellectual disabilities experience when they consider and decide to seek medical help from their GP, and thus the areas where they could benefit from support through such an online intervention.

Hence, we undertook this explorative study as input for the development of a supporting online intervention, focusing on the following research questions:

- How do people with intellectual disabilities respond to a health complaint and assess its severity?

- In what ways do they use health information in their decision to seek medical help?

- What kind of experiences do people with intellectual disabilities have with preparing for and participating in a consultation with their GP?

- What is the role of social support in all stages around a GP consultation? 
Oosterveld-Vlug, M., Oldenkamp, M., Mastebroek, M. What difficulties do people with mild intellectual disabilities experience when seeking medical help from their GP? A qualitative study. Journal of Applied Research in Intellectual Disabilities: 2020, 34(1), p. 178-189

Box 1 Setting

In the Netherlands, there are approximately 142,000 people with ID (an IQ of less than 70) (VGN, 2017). Most of them receive some sort of long-term care or support. Types of service provision vary from floating support several hours a day or a week to people living on their own or with family, to 24-hour staffed residential care. The GP is the principle physician for most people with ID, at least those who are not in residential care. GPs can refer patients to specialized ID physicians if needed. The type and amount of support determine to some extent whether support workers - trained in social work or nursing - attend GP appointments, with people with floating support receiving less support in visiting their GP.

\section{Methods}

\subsection{Study design}

A qualitative descriptive study (Sandelowski, 2000) was set up for the purpose of exploring and describing the experiences of people with intellectual disabilities when they consider and seek medical help from a GP. Individual semi-structured interviews with people with mild intellectual disabilities and relatives of people with mild intellectual disabilities were conducted and analysed following the principles of thematic analysis (Boeije, 2010; Braun \& Clarke, 2006).

\subsection{Procedures}

Participants were recruited among members of a Dutch nationally representative panel of people with intellectual disabilities, which was established in 2006 by the National Institute of Health Services Research (Nivel). The panel consists of approximately 550 people with intellectual disabilities and approximately 360 representatives - mainly relatives or friends (Frankena et al., 2018; Nivel, 2019). Approximately 50\% of the representatives are related to a person with intellectual disabilities who is also a panel member. A structured interview is conducted biannually among panel members with intellectual disabilities, in which their views on societal participation are discussed. Representatives receive annual questionnaires on the societal participation of the person with intellectual disabilities whom they represent.

The interviews conducted for this study were in addition to the biannual face-to-face interviews and annual questionnaires. The selection criteria for people with intellectual disabilities were (a) having mild intellectual disabilities (an IQ between 55 and 70), as they are more likely than people with more severe intellectual disabilities to live independently and need to organize their medicalhelp themselves and (b) having a GP as their principal physician. Representatives were eligible for recruitment if they represented a person with intellectual disabilities who fulfilled the selection criteria above. We expected that the views of the representatives would complement the information that we gathered from the people with intellectual disabilities themselves. To maximize variation in answers, we excluded representatives who were directly related to a person with mild intellectual disabilities already participating in the study.

\section{[Table 1]}

Eligible panel members were divided into categories based on sex and age. They were all aged 18 or older. We randomly selected people from each category and invited them to participate in the study. From November to December 2016, 22 people with mild intellectual disabilities and 7 representatives of persons with mild intellectual disabilities were invited based on this selection. 
Oosterveld-Vlug, M., Oldenkamp, M., Mastebroek, M. What difficulties do people with mild intellectual disabilities experience when seeking medical help from their GP? A qualitative study. Journal of Applied Research in Intellectual Disabilities: 2020, 34(1), p. 178-189

They first received information about the study by post and were subsequently called by a research assistant who asked whether they were willing to participate and answered any questions they might have. If the response was positive, the interview was planned at a time and place they found convenient. If the response was negative, we selected another person from the same category and invited him/her. The reasons individuals gave for not participating were that they did not feel like participating or were too busy. Within the context of the study, we expected that between 15 and 20 interviews would lead to data saturation (Guest, Bunce, \& Johnson, 2006). 16 interviews were conducted: 12 with people with mild intellectual disabilities and 4 with representatives. All participants provided written informed consent.

\subsection{Data collection}

All interviews were conducted in December 2016 and January 2017 by the second author (MO). The interviews were guided by a topic list (see File S1), which we developed together with three experts in the field of intellectual disabilities (one person with mild intellectual disabilities, one coach of people with intellectual disabilities and one GP) to ensure that it fitted the experiences, perceptions and language use of people with mild intellectual disabilities. The interviews focused on four main steps in the process of seeking and receiving medical help from a GP: (a) when a health problem occurs; (b) the decision whether or not to consult a GP; (c) making a doctor's appointment and preparing for it; and (d) the GP consultation itself. The nine domains of health literacy as defined by Osborne et al. (2013) served as a basis for the questions within these four topics. The interviews took place at the interviewees' homes, lasted on average $35 \mathrm{~min}$ and were audio-taped and transcribed verbatim with the permission of the interviewee.

\subsection{Data analysis}

Interview transcripts were coded with the aid of MAXQDA software version 11 (MAXQDA 11, Berlin, Germany). Following the principles of thematic analysis (Table 1), transcripts were first read and reread to become familiar with the data (Boeije, 2010; Braun \& Clarke, 2006). Then, codes were ascribed to meaningful text units, and codes were grouped together to search for themes among them. The emerging themes were constantly compared with the content of the interview transcripts. After 12 interviews, the code list no longer changed with each subsequent interview, indicating that data saturation has been achieved. The second author (MO) coded all interviews. In addition, to ensure the reliability of the coding procedure, 10 interviews were coded independently by the second author and two of the other co-authors (MOV and HB). This revealed a high degree of consensus between the different coders; disagreements between coders were small and resolved by discussion.

\subsection{Validation of the findings}

To validate the findings and to make a first step in translating these into specific content for the online intervention, we discussed the results with a group of potential users of the online intervention: six people with mild intellectual disabilities who were recruited via a Dutch interest group for people with intellectual disabilities. All themes and subthemes that arose from the interviews were recognized by this group. In addition, six experts in the field of intellectual disabilities care reflected on the results and cross-checked them; the experts comprised three who had already been involved in designing the topic list, one specialized intellectual disabilities physician (MM) and two additional support workers.

\section{Results}

Table 2 shows the participants' characteristics. The interviewed people with mild intellectual disabilities were aged between 28 and 70 , and half of them were male. The interviewed 
Oosterveld-Vlug, M., Oldenkamp, M., Mastebroek, M. What difficulties do people with mild intellectual disabilities experience when seeking medical help from their GP? A qualitative study. Journal of Applied Research in Intellectual Disabilities: 2020, 34(1), p. 178-189

representatives were either the parent(s) or sister of a person with intellectual disabilities. They were not related to any of the participating persons with mild intellectual disabilities. The following four sections describe the areas in which factors may hinder or support the capacity of people with mild intellectual disabilities to manage their health and seek care from their GP, namely (a) dealing with health complaints, (b) searching and processing health information, (c) interaction with the GP, and (d) involvement of support workers and relatives. To illustrate the themes, relevant quotes were chosen and translated, with the translation corrected by a professional translator.

\subsection{Dealing with health problems}

There was considerable variation between people with mild intellectual disabilities in how they reacted to and dealt with complaints and health problems, from instantly asking their support worker or GP for help when experiencing the slightest health complaint, to neglecting symptoms or not acknowledging them. Reluctance to consult the GP was a recurring aspect within the interviews. It was reflected two important styles of dealing with health problems: "watchful waiting" and "not responding proactively to abnormal symptoms."

\subsubsection{Watchful waiting}

Participants indicated that they, or their relative with intellectual disabilities, did not feel like talking about and responding to their health problem immediately, but preferred to observe their complaints for a while hoping that a GP visit would not be necessary. They said they took an aspirin, went to bed or took things easy if they were not feeling well. The reasons they gave for not going to the GP immediately were that they assumed that their complaints would probably disappear of their own accord, for example in the case of a recurring complaint like an annual sore throat, or when people in the neighbourhood experienced similar health problems, for example in the case of a flu epidemic.

However, there might be a moment when they decided to go to their support worker or GP after all. This mainly happened when their complaints did not go away or got worse, or when they suffered from the complaints a lot.

I postpone that sometimes, when I'm really suffering from it, then I wait and see for a few days first. If it's still there after the weekend, then I'm on the phone like: 'I want to make an appointment, because I've suffered from this for quite a while now'.

(Woman with mild ID, aged 33)

[Table 2]

Finally, I had this signal in my head, that I indicated I can't bear it [the pain] anymore. You want to keep it hidden, but this signal told me that I really had to go to the GP. First I wanted to ignore it, but then it became too painful. (...) Sometimes I talk too little. I don't want to talk or need to talk all the time. Then I think 'whatever, never mind'.

(Woman with mild ID, aged 56)

\subsubsection{Not responding proactively to abnormal symptoms}

Participants also described situations in which they actually knew that they should visit a GP, but did not feel like going, for example because they were reluctant with regard to what would happen or what they would hear. In situations like these, it could be helpful if people in the participant's network insisted on the importance of visiting a GP. 
Oosterveld-Vlug, M., Oldenkamp, M., Mastebroek, M. What difficulties do people with mild intellectual disabilities experience when seeking medical help from their GP? A qualitative study. Journal of Applied Research in Intellectual Disabilities: 2020, 34(1), p. 178-189

For example, I had a wart under my chin and my mother had already said a few times that I should visit the GP. 'Get it removed'. I was like whatever, I'm not doing that. And the support workers also said: 'It can get serious, so get it removed'. Then I made an appointment for that, by myself.

Interviewer: So actually, because others were saying that, you went after all?

Participant: Yes, but more to stop the meddling. I was like whatever, you know. (...) And it works quite well, because then it gets annoying, and then I'm already like ok, ok, ok, I'll go.

(Woman with mild ID, 28 years)

There was also a group of people with mild intellectual disabilities for whom it was hard to acknowledge their complaints, to contemplate what they should do, and to decide whether to visit a GP or not. Relatives of people with intellectual disabilities stressed this more than the people with intellectual disabilities themselves.

As soon as he feels unwell, he gets nervous and buries his head in the sand. He is like: 'Never mind, it will go away by itself'. He denies his complaints, because he doesn't want them to be real.

(Parents of man (aged 27) with mild ID)

Another example comes from a relative who explained that she had to read the signals carefully to find out if her brother felt all right, as he would never start talking about it of his own accord. This could have serious consequences:

He will never tell us when he isn't feeling well. Because he can't handle it when something doesn't work as it's supposed to, whether with machines, or his own body. He doesn't want to acknowledge that. (...) One day, he burned his belly. He had heated up hotdogs, which went wrong. They ended up on his belly, and he didn't say anything about it because he felt so stupid about it. (...) And then suddenly I saw what was going on, through his shirt, you know, it was wet. 'What did you do? Have you spilled something?'. And then he had a real scald on his belly.

(Sister of man (aged 57) with mild ID)

\subsection{Searching and processing health information}

Except for the group of persons with intellectual disabilities for whom it is difficult to acknowledge their complaints, interviewees said that health information played a significant role in the way specific health complaints were handled. More specifically, people with mild intellectual disabilities used health information as input for their decision on whether or not to end their period of "watchful waiting" and consult a GP. Sources of health information that were commonly used were as follows: the Internet ("Dr. Google") and support workers or relatives.

First I look at my complaints for a while and if I think, I'll check the internet and then I can't find the right information, $I^{\prime} l l$ ask my friend to help me or l'll call the support workers. 'Hello, I suffer from such and such a thing, what can I do?' or 'Do you have advice for me?'

(Woman with mild ID, aged 33) 
Oosterveld-Vlug, M., Oldenkamp, M., Mastebroek, M. What difficulties do people with mild intellectual disabilities experience when seeking medical help from their GP? A qualitative study. Journal of Applied Research in Intellectual Disabilities: 2020, 34(1), p. 178-189

Not every participant, however, did possess a computer with an Internet connection or had sufficient computer skills. But the ones who did have the Internet at their disposal-the majority of the interviewees - said that they found it challenging to search for health information on the Internet. Three reasons were mentioned.

\subsubsection{Online health information: too much to handle}

Participants pointed out that the amount of health information available on the Internet made it really hard to assess whether the information was reliable, and whether it applied to their situation. The overload of information on the Internet caused them to become despondent and take no further action:

Participant: There are so many things that can be found on Google that sometimes I don't know what I suffer from. For example, when your throat hurts, it could be an inflammation of the throat or so on, you don't know. One says this, another says that.

Interviewer: And are you able to make a choice?

Participant: No, then I'm already like never mind, it will go away by itself.

(Man with mild ID, aged 31)

Sometimes, the overwhelming amount of information and the lack of clarity concerning the reliability were a reason to consult their GP whom they perceived as the most reliable source of information.

The internet, you find a lot there, but you'll always think: is that correct? Sometimes I have my doubts; is that really true? Then I am better off going to my GP, he is the one who really knows.

(Woman with mild ID, aged 33)

\subsubsection{Too difficult to understand}

Health information was often perceived as difficult and therefore hard to understand, resulting in persons with intellectual disabilities giving up quickly on reading and searching for information. Moreover, not being able to understand the information could be difficult to deal with, as it could confirm their idea of not being smart enough and could underline their status as someone with intellectual disabilities:

The level at which they explain things on the internet, that's too high, they [people with mild ID] don't get that. The explanation should be in a childish way. (...). It needs to be understandable for him, because otherwise he will close up after two or three lines, then he says things like: 'whatever, l'll look for something else'. (...) It's hard to deal with, he's like: 'I'm not smart enough, I'm intellectually disabled'. That bothers him, I guess.

(Parents of a man (aged 27) with mild ID)

\subsubsection{Protecting oneself against assuming the worst}

According to the interviewees, a third reason for not searching for health information was that people with intellectual disabilities wanted to avoid being confronted by all sorts of horrible information and images, which would make them think something really bad was going on or that they were very ill.

Because sometimes I'm quite a hypochondriac. So, when I experience complaints in my stomach, or in my gut, or wherever, or I can't move my wrist well, then I assume that 
Oosterveld-Vlug, M., Oldenkamp, M., Mastebroek, M. What difficulties do people with mild intellectual disabilities experience when seeking medical help from their GP? A qualitative study. Journal of Applied Research in Intellectual Disabilities: 2020, 34(1), p. 178-189

something bad is going on. (...) If I searched for information then, I would only think 'Oh no, I am seriously ill'.

(Woman with mild ID, aged 28)

However, not all people with intellectual disabilities were aware that the information and images on the Internet could cause them to excessively worry. Nor did they comprehend that could protect themselves against this. A mother explained how searching on the Internet only made her daughter feel more nervous:

She searches the internet to find out what is going on with her, what can be done about it, and what other symptoms you may get, and so on. Yes, and that makes her nervous, because she reads stuff she doesn't understand. And that has a negative effect on her. Because she keeps thinking about it.

(Mother of a woman (aged 25) with mild ID)

\subsection{Interaction with the GP}

There was considerable variation in the extent to which the people with mild intellectual disabilities were able to interact with the GP. This largely depended on whether the person with intellectual disabilities had sufficient telephone skills to make an appointment, was able to describe health complaints clearly and was able to remember the consultation information afterwards.

\subsubsection{Having sufficient telephone skills}

Most participants with intellectual disabilities stated that they made appointments with the GP themselves. They explained that they knew exactly how to do this, whom they got to speak to, and what they needed to say when calling. Some of them prepared for the call by writing things down. Other participants said that their support worker made appointments with the GP for them, because they were not able to do this themselves due to problems with speech, lack of self-confidence or difficulties with dialling.

The support workers do that [making an appointment], if you want to go to the GP. I don't dare do that myself. (...) Dialling a phone number is something I find difficult, then you have to dial another number to make an appointment, and then another one.

(Man with mild ID, aged 31)

\subsubsection{Describing health complaints}

Once the GP appointment had been made, hardly any of the participants said that they prepared for this by writing questions or concerns down. The participants who made the appointments themselves in particular pointed out that they just went to the GP and asked their questions when they got there. Some, however, thought that preparing for the consultation would be a good idea, to make sure they could express themselves clearly. When the support workers made appointments, the person with intellectual disabilities received a note from them which they could hand over to their GP, stating the reason for visiting the GP in case the person with intellectual disabilities could not express him/herself clearly. The GP could also use this note to write down what had been discussed and agreed on, to inform support workers about this as well.

Then I'll receive a letter from the support workers. And then they [the support workers] let him [the GP] write on it as well. That's easy. About what is going on, for example. (...) Yes that's better. If you have to explain it yourself and you explain it wrongly, that would get difficult. That's why it is better to do it this way [with a letter] for people with disabilities. 
Oosterveld-Vlug, M., Oldenkamp, M., Mastebroek, M. What difficulties do people with mild intellectual disabilities experience when seeking medical help from their GP? A qualitative study. Journal of Applied Research in Intellectual Disabilities: 2020, 34(1), p. 178-189

(Man with mild ID, aged 50)

Although some participants with intellectual disabilities stated that they did fine when it came to explaining their health problems, the interviews showed this was not the case for everyone; multiple participants with intellectual disabilities or their representatives indicated that they did not always succeed in telling the GP what they would like to tell him or her, or in asking the questions they would like to ask, especially when the problems were more complex. Participants with intellectual disabilities tended to forget things, for example because they were shy, got nervous, possibly even panicked when visiting the GP, or because they felt time pressure.

Well, she is shy, and especially because he [the GP] is new again, that's a bit of a pity of course. Yes, sometimes she can't describe it well at that moment, then she panics a bit.

(Mother of daughter (aged 27) with mild ID)

At such times, the presence of support workers or relatives was regarded as important. They could clarify things or provide mental support to the person with intellectual disabilities. When this occurred, participants said, however, that they found it important for the conversation to be held primarily with the person with intellectual disabilities, instead of with the accompanying support worker or relative.

\subsubsection{GP-related factors facilitating communication and understanding}

Several GP-related factors can facilitate the GP-patient communication and understanding. For example, the use of simple language was regarded as important. Participants pointed out that they understood their GP most of the time, and that he or she did not use language that was too difficult. It helped when the GP was familiar with treating people with intellectual disabilities.

Participant: Sometimes he [the GP] uses these medical terms. Then I think, man, speak Dutch! Interviewer: Can you say that to your GP?

Participant: Yes, and then he says 'I'll try to remember, and if I don't speak clearly, you just need to remind me.'

(Man with mild ID, aged 52)

Also having sufficient time allocated for the appointment and the existence of a bond of trust between the patient and the GP-which was often stronger if they had known each other for a longer period of time-could facilitate the communication. Participants indicated that both factors helped them to feel less rushed, to feel listened to and to ask questions if they did not understand the GP.

Participant: He knows me. He asks how l'm doing and what my problem is. (...).

Interviewer: And does he listen carefully to you?

Participants: Yes, definitely. And he is very good in recognizing what's wrong with me and what he can do for me.

(Woman with mild ID, aged 28)

Participants explained that their GP-sometimes on explicit request of the person with intellectual disabilities - wrote things down on paper or sent an e-mail in order to remind the person with intellectual disabilities of what the GP had discussed with them, for example about exercises or medication. They indicated that such notes were also useful for the support workers, who often wanted to know what had been discussed. One of the participants suggested audiotaping the entire consultation. Another option to help remind the person with intellectual disabilities of what had 
Oosterveld-Vlug, M., Oldenkamp, M., Mastebroek, M. What difficulties do people with mild intellectual disabilities experience when seeking medical help from their GP? A qualitative study. Journal of Applied Research in Intellectual Disabilities: 2020, 34(1), p. 178-189

been discussed was for GPs to summarize the discussion at the end of the appointment and actively check that the patient's had understood.

Well, they [GPs] could repeat the conclusion, and then ask 'What do you suffer from? What's going to happen now? Do you get medicines or should you drink something else in order to get your bowels functioning well?' Just repeat it, so that they'll remember.

(Mother of daughter (aged 27) with mild ID)

\subsection{Involvement of support workers and relatives}

Interviewees described how support workers and relatives were, to a greater or lesser extent, involved in every stage of the process of assessing health complaints and seeking medical help from a GP. Depending on the frequency with which participants had contact with their support workers and relatives, involving them in their health problems seemed to be something that was more or less selfevident. The role of support workers and relatives could be seen in three main aspects.

\subsubsection{Signalling and monitoring health problems}

Support workers and relatives had an important role in signalling and monitoring health problems and deciding whether medical help from a GP was needed, especially in persons with intellectual disabilities for whom it is hard to acknowledge and assess their complaints themselves.

She knows that she should go to the support workers when she is in the group home, and they will assess whether there actually is a problem or not. And then the GP will be called. The support workers are the ones who determine whether she needs to see a GP. And when she's at home, then it's us.

(Mother of daughter (aged 25) with mild ID)

Furthermore, support workers helped persons with intellectual disabilities to become aware of their health by regularly asking them whether they had a health complaint. The support worker might also notice health complaints themselves:

Well, the support workers sometimes notice health problems during the care they give. Once, he had a weird spot of eczema on his side, and one of them noticed that. And then she made an appointment for him with the GP.

(Parents of a man (aged 27) with mild ID)

\subsubsection{Providing support during GP consultations}

A second aspect where support workers and relatives could play a role was during an appointment with the GP. One reason was to support the person with intellectual disabilities, to help them overcome anxiety and to give them more confidence.

That happens when I can't describe my health problem. Or when I find that difficult. Or if I need to cry, or if I'm worried about seeing the GP for whatever reason. Then someone comes with me.

(Woman with mild ID, aged 28)

Another reason for accompanying a person with intellectual disabilities is to have a second person listening in so as to know exactly what has been said and agreed on, just in case the person with intellectual disabilities is unable to pass on the consultation information properly themselves. 
Oosterveld-Vlug, M., Oldenkamp, M., Mastebroek, M. What difficulties do people with mild intellectual disabilities experience when seeking medical help from their GP? A qualitative study. Journal of Applied Research in Intellectual Disabilities: 2020, 34(1), p. 178-189

She tends to make it bigger than it is. So when she goes to the GP, someone has to join her to hear exactly what has been said, because otherwise she exaggerates or changes what has been agreed on.

(Mother of daughter (aged 25) with mild ID)

Last, support workers or relatives could serve as a back-up during the consultation in case the person with intellectual disabilities forgot to mention certain health complaints, or explain things that were unclear.

Because especially when she is so tense, she forgets a lot, and doesn't pay enough attention. So then she likes it if someone is there who can listen as well. And who can answer for her if she doesn't know it herself.

(Mother of daughter (aged 25) with mild ID)

\subsubsection{Ensuring treatment adherence}

A third role for support workers and relatives that could be discerned from the interviews lay in reflecting on what the GP had said and what had been agreed on in terms of medication, exercises or some other form of follow-up. By doing this, they tried to ensure that the person with intellectual disabilities was aware of the diagnosis and adhered to the treatment plan.

Well, he is not fully aware of the arrangements being made. And we pick up on that later, when we're back from the GP. Then we'll have some conversation afterwards 'Well, this or that has occurred, and this or that will happen now, do you understand that?' Because we can't always work out what has stuck in his head.

(Parents of a man (aged 27) with mild ID)

\section{Discussion}

This study explored the considerations and behaviours of people with mild intellectual disabilities when faced with a health problem and when seeking help from their GP. We found wide variation in the extent to which people with mild intellectual disabilities were able to manage their own health and seek help from their GP. Whereas some were quite self-reliant, others experienced difficulties in one or more of the following activities: adequately responding to a health complaint, processing health information, communicating with the GP and retaining information given in the consultation. Most participants needed support workers or relatives to support them in these activities. Our study gives a better understanding of the nature of these difficulties and provides recommendations to support the health literacy of people with mild intellectual disabilities in all stages around a GP consultation.

\subsection{Responding to a health complaint}

Difficulties were experienced in assessing the severity of a health complaint after its initial appearance and acknowledging that medical help is needed. Our finding that people with mild intellectual disabilities may not discuss aberrant health signs or may not deal proactively with abnormal symptoms corresponds with earlier studies (Mastebroek et al., 2017; Mastebroek, Naaldenberg, Van den Driessen Mareeuw, Lagro-Janssen, \& van Schrojenstein Lantman-de Valk, 2016), and implies that they are more at risk of having undiagnosed and untreated conditions (Baxter et al., 2006; van Schrojenstein Lantman-de Valk \& Walsh, 2008). It is therefore important to encourage people with intellectual disabilities to discuss their health complaints with others, in order to find out what is causing the complaint and its severity. 
Oosterveld-Vlug, M., Oldenkamp, M., Mastebroek, M. What difficulties do people with mild intellectual disabilities experience when seeking medical help from their GP? A qualitative study. Journal of Applied Research in Intellectual Disabilities: 2020, 34(1), p. 178-189

Health information on the Internet could be a helpful source when trying to determine the origin and severity of a health complaint. However, our study revealed that people with mild intellectual disabilities had difficulties in processing information from this medium due to insufficient reading skills, or because of the overwhelming number of available websites and their use of overly complicated language. These experiences do not only apply to people with intellectual disabilities; even people with high levels of health literacy often have low self-efficacy in their ability to find online health information or in estimating its quality (Ghaddar, Valerio, Garcia, \& Hansen, 2012; Knapp, Madden, Marcu, et al., 2011; Knapp, Madden, Wang, Sloyer, \& Shenkman, 2011). Emphasizing that this is difficult for many people, could boost the self-esteem of people with mild intellectual disabilities. Nevertheless, it is important that health information should be offered in an easy-to-read format, with simple text accompanied by pictures and audio. In addition to this, effective educational strategies can help individuals with limited health literacy learn how to use eHealth services, how to search for information effectively and how to evaluate the quality of online health information (Xie, 2012).

\subsection{GP-patient interaction}

Our study showed that difficulties were also experienced in consulting a GP-both before, during and after an appointment. Participants had difficulties with various activities, such as dialling the phone number and choosing the right option from the menu of options, describing the specifics of their health complaint and understanding and retaining the GP's explanations. Our findings corroborate earlier research (e.g. Mastebroek, Naaldenberg, Van den Driessen Mareeuw, Leusink, et al., 2016; Ziviani, Lennox, Allison, Lyons, \& Del Mar, 2004). For example, in an interview study among GPs, GPs felt that people with intellectual disabilities often had difficulties in expressing the nuances of their complaints, reflecting on their feelings and understanding the GP's questions, which sometimes led to unnecessary and burdensome tests and a longer time to identify the medical problems and start effective treatment (Mastebroek, Naaldenberg, Van den Driessen Mareeuw, Leusink, et al., 2016). Hardly, any of our participants with intellectual disabilities prepared for an appointment by noting down complaints and questions in advance. A better preparation should therefore be more encouraged by support workers or relatives as this can facilitate people the communication between people with intellectual disabilities and GPs (Mastebroek et al., 2017).

Because we found that a bond of trust between the GP and the person with intellectual disabilities could facilitate the doctor-patient communication, it could be helpful for them to get acquainted with each other before an actual health problem occurs. In such a meeting, in which the person with intellectual disabilities is ideally accompanied by a relative or support worker, the personal situation and medical history could be discussed, and the GP could attune his/her communication to the language comprehension of the person with intellectual disabilities. More exposure to people with intellectual disabilities and experiential learning rather than theoretical education have been requested by GPs themselves in order to optimize their communication and caregiving with regard to this group of patients (Wilkinson, Dreyfus, Cerreto, \& Bokhour, 2012).

An additional finding was that more consultation time could facilitate the GP-patient communication. A recommendation therefore is to make it common practice for persons with intellectual disabilities to book a double appointment, which allows sufficient time for them to describe the health complaint properly and to check whether they have understood the diagnosis and treatment plan correctly. Loss of important consultation information afterwards may lead to poor patient follow-up and treatment adherence (Cardol, Rijken, van Schrojenstein Lantman - de Valk, 2012; Martin, Williams, Haskard, \& Dimatteo, 2005; Mastebroek, Naaldenberg, Van den Driessen Mareeuw, Leusink, et al., 2016). The "teach-back method," in which patients are asked to repeat the main message in their own words, could help people with intellectual disabilities remember what a GP explained. In other contexts and patient groups, the teach-back method has led 
Oosterveld-Vlug, M., Oldenkamp, M., Mastebroek, M. What difficulties do people with mild intellectual disabilities experience when seeking medical help from their GP? A qualitative study. Journal of Applied Research in Intellectual Disabilities: 2020, 34(1), p. 178-189

to promising results in patients' disease-specific knowledge, adherence and self-efficacy (Ha Dinh, Bonner, Clark, Ramsbotham, \& Hines, 2016; Yen \& Leasure, 2019). It can also be valuable for support workers or relatives to reflect on what was discussed during the GP consultation. Therefore, sharing information with support workers or relatives via a letter, e-mail or audiotape is recommended.

\subsection{Indispensable role of support workers and relatives}

So far, the nature of the difficulties people with mild intellectual disabilities experience when they seek help from their GP is not that different from the difficulties people with limited health literacy in general may experience. However, this ought not to be surprising as people with mild intellectual disabilities are one of the core subgroups within the group of people with limited health literacyalongside older persons, people with a low educational level and people with a migrant background. More than these other groups, people with intellectual disabilities are characterized by limited language comprehension and slowness of understanding. In addition, health problems and comorbidities may present differently in people with intellectual disabilities. GPs are not always familiar with these different presentations. Therefore, people with mild intellectual disabilities often rely on support from support workers or relatives throughout the process of assessing health complaints and seeking medical help from a GP: in monitoring health complaints, in deciding whether or not medical help is needed, in interacting with the GP and in reflecting on the GP consultation. Because of their roles as monitors and sources, collectors, interpreters, carriers and record keepers of health information, support workers and relatives can be regarded as indispensable links between GPs and people with intellectual disabilities in the exchange of health information. Therefore, the availability of information on the health of the person with intellectual disabilities often depends on the availability of support workers and relatives (Mastebroek, Naaldenberg, Van den Driessen Mareeuw, Lagro-Janssen, et al., 2016). This dependence runs a risk of people with intellectual disabilities becoming too reliant, or it may lead to support workers taking over the consultation and to privacy infringements (Murphy, 2006). It also exemplifies why continuity in support workers and training them to adequately fulfil these roles is of specific importance in caring for people with intellectual disabilities (Fredheim, Haavet, Danbolt, Kjønsberg, \& Lien, 2013; Murphy, 2006).

\subsection{Supporting the health literacy of people with mild intellectual disabilities through an online intervention}

As described in the introduction, an online intervention seems a suitable way to enhance the health literacy of people with intellectual disabilities, as well as of other people with limited health literacy (Kim \& Xie, 2017). The online intervention that we planned in this project was similar to other online interventions specifically designed for people with intellectual disabilities. These interventions on a variety of topics (e.g. about how to use the public transport system or about the effects of drugs and alcohol) are familiar to people with intellectual disabilities. They combine visual information with audio and use clear, short messages. Preparations for this project showed a need for an online intervention supporting people with intellectual disabilities in seeking care from their GP.

The insights we gained from this interview study were therefore used as input for the recently developed Dutch website "Going to your GP" (www.naarj ehuis arts.nl). The majority of the abovementioned recommendations to support the health literacy of people with mild intellectual disabilities have been incorporated in this website (Garritsen, Boeije, \& Oldenkamp, 2019). The website consists of four different modules. There are two modules containing easy-to-understand information and tips about how to cope with health complaints or about the course of events at a general practice. In a third module, people practice a telephone call with the GP assistant. A fourth module maps one's health complaints onto an interactive chart of the human body, which can be printed and shown to the GP. On a small scale, the website has been tested for user-friendliness and for its contribution to the health literacy of people with mild intellectual disabilities, with promising 
Oosterveld-Vlug, M., Oldenkamp, M., Mastebroek, M. What difficulties do people with mild intellectual disabilities experience when seeking medical help from their GP? A qualitative study. Journal of Applied Research in Intellectual Disabilities: 2020, 34(1), p. 178-189

results (Garritsen et al., 2019). Further research with a larger group of people with intellectual disabilities is needed to establish the effects of the online intervention.

\subsection{Methodological considerations}

Examining the perspectives of people with mild intellectual disabilities and their relatives helped substantially in elucidating the health literacy skills of people with mild intellectual disabilities in all stages around a GP consultation, including the stages that are unobserved by the GP. Interviewing people with intellectual disabilities posed particular challenges. Interviews with representatives generally contained more thick descriptions and were rich in information. They facilitated interpretation of what was said by the persons with mild intellectual disabilities. As such, these two sources were complementary. Data saturation was achieved, and results were confirmed in an additional discussion group with people with mild intellectual disabilities. In addition, cross-checking with experts in the field helped deepen the contextual understanding of our results. Interviewing GPs or support workers was beyond the scope of this study, but could be relevant in future research. For instance, to provide additional insights into how factors relating to the organization of support and GP practices affect the health literacy of people with intellectual disabilities.

\section{Conclusion}

People with mild intellectual disabilities experience difficulties to a greater or lesser extent in adequately responding to a health complaint, in processing health information, in communicating with a GP and in retaining information from the consultation. They often rely on support workers or relatives to support them in one or more of these activities. Recommendations to enhance the health literacy of people with mild intellectual disabilities have been incorporated in an online intervention, which aims to support people with intellectual disabilities to fulfil an autonomous and responsible role when it comes to their health and when seeking medical help from their GP.

\section{Acknowledgements}

We would like to thank all the people with ID and relatives for their participation, and Clare Wilkinson of Tessera Translations for critically revising the English.

\section{Conflict of interest}

The authors declare that they have no conflicting interests.

\section{Orcid}

Mariska Oosterveld-Vlug https://orcid.org/0000-0003-3911-1536

\section{References}

Baxter, H., Lowe, K., Houston, H., Jones, G., Felce, D., \& Kerr, M. (2006). Previously unidentified morbidity in patients with intellectual disability. British Journal of General Practice, 56, 93-98.

Berkman, N. D., Davis, T. C., \& McCormack, L. (2010). Health literacy: What is it? Journal of Health Communication, 15, 9-19. https://doi.org/10.1080/10810 730.2010.499985

Berkman, N. D., Sheridan, S. L., Donahue, K. E., Halpern, D. J., \& Crotty, K. (2011). Low health literacy and health outcomes: An updated systematic review. Annals of Internal Medicine, 155, 97-107. https://doi.org/10.7326/0003-4819-155-2-20110 7190-00005

Berkman, N. D., Sheridan, S. L., Donahue, K. E., Halpern, D. J., Viera, A., Crotty, K., ... Viswanathan, M. (2011). Health literacy interventions and outcomes: An updated systematic review. Evidence Report/Technology Assessment, 199, 1-941. 
Oosterveld-Vlug, M., Oldenkamp, M., Mastebroek, M. What difficulties do people with mild intellectual disabilities experience when seeking medical help from their GP? A qualitative study. Journal of Applied Research in Intellectual Disabilities: 2020, 34(1), p. 178-189

Boeije, H. (2010). Analysis in qualitative research. Los Angeles, CA: SAGE. Braun, V., \& Clarke, V. (2006). Using thematic analysis in psychology. Qualitative Research in Psychology, 3, 77-101. https://doi.org/10.1191/14780 88706 qp063oa

Cardol, M., Rijken, M., \& van Schrojenstein Lantman-de Valk, H. M. J. (2012). People with mild to moderate intellectual disability talking about their diabetes and how they manage. Journal of Intellectual Disability Research, 56, 351-360. https://doi.org/10.1111/j.1365-2788.2011.01472.x

Einfeld, S. L., Piccinin, A. M., Mackinnon, A., Hofer, S. M., Taffe, J., Gray, K. M., ... Tonge, B. J. (2006). Psychopathology in young people with intellectual disability. The Journal of the American Medical Association, 296, 1981-1989. https://doi.org/10.1001/jama.296.16.1981

Engels, J., Wijenberg, E., \& Schepers, B. (2015). Zelfmanagement en beperkte gezondheidsvaardigheden. Handreiking voor huisartsen, praktijkondersteuners, diëtisten en fysiotherapeuten. Utrecht, The Netherlands: Vilans.

Frankena, T. K., Naaldenberg, J., Bekkema, N., van Schrojenstein Lantman-de Valk, H. J. M., Cardol, M., \& Leusink, G. (2018). An exploration of the participation of people with intellectual disabilities in research - a structured interview survey. Journal of Applied Research in Intellectual Disabilities, 31, 942-947. https://doi.org/10.1111/jar.12453

Fredheim, T., Haavet, O. R., Danbolt, L. J., Kjønsberg, K., \& Lien, L. (2013). Intellectual disability and mental health problems: A qualitative study of general practitioners' views. British Medical Journal Open, 3, e002283. https://doi.org/10.1136/bmjop en-2012-002283

Garritsen, H. H., Boeije, H. R., \& Oldenkamp, M. (2019). Website 'Naar je huisarts' voor mensen met een lichte verstandelijke beperking: Praktijktoets naar de ondersteuning van gezondheidsvaardigheden. Nederlands Tijdschrift Voor De Zorg Aan Mensen Met Verstandelijke Beperkingen, 1, 36-47.

Ghaddar, S. F., Valerio, M. A., Garcia, C. M., \& Hansen, L. (2012). Adolescent health literacy: The importance of credible sources for online health information. The Journal of School Health, 82, 28-36. https://doi.org/10.1111/j.1746-1561.2011.00664.x

Guest, G., Bunce, A., \& Johnson, L. (2006). How many interviews are enough?: An experiment with data saturation and variability. Field Methods, 18, 59-82. https://doi.org/10.1177/15258 22X05 279903

Ha Dinh, T. T., Bonner, A., Clark, R., Ramsbotham, J., \& Hines, S. (2016). The effectiveness of the teach-back method on adherence and self-management in health education for people with chronic disease: A systematic review. JBI Database of Systematic Reviews and Implementation Reports, 14, 210-247. https://doi.org/10.11124/ jbisr ir-2016-2296

Jenaro, C., Flores, N., Cruz, M., Carmen Pérez, M., Vega, V., \& Torres, V. A. (2018). Internet and cell phone usage patterns among young adults with intellectual disabilities. Journal of Applied Research in Intellectual Disabilities, 31, 259-272. https://doi.org/10.1111/jar.12388

Kim, H., \& Xie, B. (2017). Health literacy in the eHealth era: A systematic review of the literature. Patient Education \& Counselling, 100, 1073-1082. https://doi.org/10.1016/j.pec.2017.01.015

Knapp, C., Madden, V., Marcu, M., Wang, H., Curtis, C., Sloyer, P., \& Shenkman, E. (2011). Information seeking behaviors of parents whose children have life-threatening illnesses. Pediatric Blood \&

Cancer, 56, 805-811. https://doi.org/10.1002/pbc.22674 Knapp, C., Madden, V., Wang, H., Sloyer, P., \& Shenkman, E. (2011). Internet use and eHealth literacy of low-income parents whose children have special health care needs. Journal of Medical Internet Research, 13, e75. https://doi.org/10.2196/jmir.1697

Krahn, G. L., Hammond, L., \& Turner, A. A. (2006). Cascade of disparities: Health and health care access for people with intellectual disabilities. Mental Retardation and Developmental Disabilities Research Reviews, 12, 70-82. https://doi.org/10.1002/mrdd.20098

Martin, L. R., Williams, S. L., Haskard, K. B., \& Dimatteo, M. R. (2005). The challenge of patient adherence. Therapeutics and Clinical Risk Management, 1, 189-199. 
Oosterveld-Vlug, M., Oldenkamp, M., Mastebroek, M. What difficulties do people with mild intellectual disabilities experience when seeking medical help from their GP? A qualitative study. Journal of Applied Research in Intellectual Disabilities: 2020, 34(1), p. 178-189

Mastebroek, M., Naaldenberg, J., Lagro-Janssen, A. L., \& van Schrojenstein Lantman de Valk, H. (2014). Health information exchange in general practice care for people with intellectual disabilities-a qualitative review of the literature. Research in Developmental Disabilities, 35, 1978-1987. https://doi.org/10.1016/j.ridd.2014.04.029

Mastebroek, M., Naaldenberg, J., Tobi, H., van Schrojenstein Lantman-de Valk, H. M. J., LagroJanssen, A. L. M., \& Leusink, G. L. (2017). Priority-setting and feasibility of health information exchange for primary care patients with intellectual disabilities: A modified Delphi study. Patient Education \& Counseling, 100, 1842-1851. https://doi.org/10.1016/j.pec.2017.04.010

Mastebroek, M., Naaldenberg, J., Van den Driessen Mareeuw, F. A., Lagro-Janssen, A. L., \& van Schrojenstein Lantman-de Valk, H. M. J. (2016). Experiences of patients with intellectual disabilities and carers in GP health information exchanges: A qualitative study. Family Practice, 32, 543-550. https://doi.org/10.1093/fampr a/cmw057

Mastebroek, M., Naaldenberg, J., Van den Driessen Mareeuw, F. A., Leusink, G. L., Lagro-Janssen, A. L., \& van Schrojenstein Lantman-de Valk, H. J. M. (2016). Health information exchange for patients with intellectual disabilities: A general practice perspective. British Journal of General Practice, 66, e720-e728. https://doi.org/10.1093/fampr a/cmw057

Murphy, J. (2006). Perceptions of communication between people with communication disability and general practice staff. Health Expectations, 9, 49-59. https://doi.org/10.1111/j.13697625.2006.00366.x

Nivel. (2019). Panel Samen Leven. Retrieved from https://www.nivel.nl/nl/panel-samen-leven Osborne, R. H., Batterham, R., Elsworth, G. R., Hawkins, M., \& Buchbinder, R. (2013). The grounded psychometric development and initial validation of the Health Literacy Questionnaire (HLQ). BMC Public Health, 13, 658. https://doi.org/10.1186/1471-2458-13-658 Ouellette-Kuntz, H. (2005). Understanding health disparities and inequities faced by individuals with intellectual disabilities. Journal of Applied Research in Intellectual Disabilities, 18, 113-121. https://doi.org/10.1111/j.1468-3148.2005.00240.x

Paasche-Orlow, M. K., \& Wolf, M. S. (2007). The causal pathways linking health literacy to health outcomes. American Journal of Health Behaviour, 31, S19-S26.

https://doi.org/10.5555/ajhb.2007.31.supp.S19

Rademakers, J. (2014). Gezondheidsvaardigheden. Niet voor iedereen vanzelfsprekend. Utrecht, The Netherlands: Nivel.

Sandelowski, M. (2000). Whatever happened to qualitative description? Research in Nursing \& Health, 23, 334-340. https://doi.org/10.1002/1098-240x(20000 8)23:4<334:aid-nur9>3.0.co;2-g

Straetmans, J. M., van Schrojenstein Lantman-de Valk, H. M. J., Schellevis, F. G., \& Dinant, G. J. (2007). Health problems of people with intellectual disabilities. British Journal of General Practice, 57, 64-66.

van Schrojenstein Lantman-de Valk, H. M. J., \& Walsh, P. N. (2008). Managing health problems in people with intellectual disabilities. British Medical Journal, 337, 1408-1412.

https://doi.org/10.1136/bmj.a2507

VGN. (2017). Feiten en cijfers. Retrieved from https://www.vgn.nl/feitenencijfers

Vilans. (2020). Kennisdossier Integrale Zorg en ondersteuning in buurt en wijk. Retrieved from https://www.kennispleingehandicaptensector.nl/gehandicaptensector/media/documents/Thema 's/Samen \%20werken\%20in\%20de\%20wijk/integrale-zorg-en-ondersteuning-kennisdossier.pdf

Webb, J., \& Stanton, M. (2008). Better access to primary healthcare for adults with learning disabilities: Evaluation of a group programme to improve knowledge and skills. British Journal of Learning Disabilities, 37, 116-122. https://doi.org/10.1111/j.1468-3156.2008.00527.x

Wilkinson, J., Dreyfus, D., Cerreto, M., \& Bokhour, B. (2012). "Sometimes I feel overwhelmed": Educational needs of family physicians caring for people with intellectual disability. Intellectual and Developmental Disabilities, 50, 243-250. https://doi.org/10.1352/1934-9556-50.3.243 
Oosterveld-Vlug, M., Oldenkamp, M., Mastebroek, M. What difficulties do people with mild intellectual disabilities experience when seeking medical help from their GP? A qualitative study. Journal of Applied Research in Intellectual Disabilities: 2020, 34(1), p. 178-189

Xie, B. (2012). Improving older adults' e-health literacy through computer training using NIH online resources. Library \& Information Science Research, 34, 63-71.

https://doi.org/10.1016/i.lisr.2011.07.006

Yen, P. H., \& Leasure, A. R. (2019). Use and effectiveness of the teach-back method in patient education and health outcomes. Federal Practitioner, 36, 284-289.

Ziviani, J., Lennox, N., Allison, H., Lyons, M., \& Del Mar, C. (2004). Meeting in the middle: Improving communication in primary health care consultations with people with an intellectual disability. Journal of Intellectual \& Developmental Disability, 29, 211-225. https://doi.org/10.1080/13668 250412331285163

\section{Supporting information}

Additional supporting information may be found online in the Supporting Information section.

How to cite this article: Oosterveld-Vlug $M$, Oldenkamp M, Mastebroek M, Boeije H. What difficulties do people with mild intellectual disabilities experience when seeking medical help from their GP? A qualitative study. J Appl Res Intellect Disabil. 2020;00:1-12.

https://doi.org/10.1111/jar.12796

\section{Tables}

Table 1 Sequential phases of analysis

\begin{tabular}{|c|c|c|}
\hline Phase & Action & Result \\
\hline $\begin{array}{l}\text { 1. Familiarizing } \\
\text { ourselves with the } \\
\text { data }\end{array}$ & $\begin{array}{l}\text { Reading and re-reading the } \\
\text { transcripts with the research } \\
\text { questions in mind. }\end{array}$ & $\begin{array}{l}\text { A rough idea of recurring patterns in the data, for example the great significant } \\
\text { role of support workers and relatives, which stood out in all stages around a GP } \\
\text { consultation (before, during and afterwards). The perspective that sensitized us } \\
\text { to examine the data was the different aspects of health literacy. }\end{array}$ \\
\hline $\begin{array}{l}\text { 2. Generating initial } \\
\text { codes within } \\
\text { the analytical } \\
\text { framework }\end{array}$ & $\begin{array}{l}\text { Indicating meaningful fragments in } \\
\text { the data. Assigning codes to these } \\
\text { meaningful units. The four stages } \\
\text { of seeking and receiving help from } \\
\text { a GP were used as an analytical } \\
\text { framework. }\end{array}$ & $\begin{array}{l}\text { The four stages of seeking and receiving help from a GP that was used as } \\
\text { analytical framework (1. when a health problem occurs; } 2 \text {. the decision whether } \\
\text { or not to consult a GP; } 3 \text {. making a doctor's appointment and preparing for } \\
\text { it; and 4. the GP consultation itself) were filled with as many codes as were } \\
\text { needed. Codes related to the use of health information and to the involvement } \\
\text { of support workers and relatives were found in several of these stages. }\end{array}$ \\
\hline $\begin{array}{l}\text { 3. Generating initial } \\
\text { themes }\end{array}$ & $\begin{array}{l}\text { Combining codes into overarching } \\
\text { themes that accurately depict the } \\
\text { data. }\end{array}$ & $\begin{array}{l}\text { Preliminary themes and subthemes overarching the four stages of seeking and } \\
\text { receiving medical help, for example. theme (1) dealing with health complaints, } \\
\text { with subthemes (a) ability to acknowledge symptoms; (b) feeling responsible for } \\
\text { own health; (c) neglecting complaints; and (d) postponing a GP visit. "Searching } \\
\text { for and processing health information" and "Involvement of support workers and } \\
\text { relatives" were generated as separate themes in this phase. }\end{array}$ \\
\hline 4. Reviewing themes & $\begin{array}{l}\text { Comparing initial themes against } \\
\text { coded data and the transcripts. }\end{array}$ & $\begin{array}{l}\text { Refinement of initial themes and subthemes, for example. (1a) ability to } \\
\text { acknowledge symptoms; (1b) feeling responsible for own health and; (1d) } \\
\text { postponing a GP visit could be clustered in the subtheme 'watchful waiting'. }\end{array}$ \\
\hline $\begin{array}{l}\text { 5. Describing themes } \\
\text { and integrating } \\
\text { them }\end{array}$ & $\begin{array}{l}\text { Describing each theme, and making } \\
\text { an integrated report of the } \\
\text { results. }\end{array}$ & $\begin{array}{l}\text { Four major themes arose as a result of the analytical effort: (1) dealing with health } \\
\text { complaints; (2) searching and processing health information; (3) interaction with } \\
\text { the GP; and (4) involvement of support workers and relatives. In these topic } \\
\text { areas, factors may hinder or support the capacity of people with mild intellectual } \\
\text { disabilities to manage their health and seek care from their GP. This gives useful } \\
\text { information about health literacy. }\end{array}$ \\
\hline
\end{tabular}


Oosterveld-Vlug, M., Oldenkamp, M., Mastebroek, M. What difficulties do people with mild intellectual disabilities experience when seeking medical help from their GP? A qualitative study. Journal of Applied Research in Intellectual Disabilities: 2020, 34(1), p. 178-189

Table 2 Characteristics of study participants

\begin{tabular}{|c|c|c|c|c|}
\hline \multicolumn{5}{|c|}{ People with mild intellectual disabilities } \\
\hline No & Age & Sex & \multicolumn{2}{|c|}{ Received support } \\
\hline 1 & 28 & Female & \multicolumn{2}{|c|}{ Once a week } \\
\hline 2 & 62 & Male & \multicolumn{2}{|c|}{ Every day } \\
\hline 3 & 70 & Male & \multicolumn{2}{|c|}{ Every day } \\
\hline 4 & 31 & Male & \multicolumn{2}{|c|}{ Twice a week } \\
\hline 5 & 65 & Male & \multicolumn{2}{|c|}{ Every day } \\
\hline 6 & 33 & Female & \multicolumn{2}{|c|}{ Once a week } \\
\hline 7 & 56 & Female & \multicolumn{2}{|c|}{ Every day } \\
\hline 8 & 63 & Female & \multicolumn{2}{|c|}{ Every day } \\
\hline 9 & 28 & Female & \multicolumn{2}{|c|}{ Every day } \\
\hline 10 & 50 & Male & \multicolumn{2}{|c|}{ (Almost) every day } \\
\hline 11 & 52 & Male & \multicolumn{2}{|c|}{ Once a week } \\
\hline 12 & 44 & Female & \multicolumn{2}{|c|}{ Every day } \\
\hline \multicolumn{5}{|c|}{ Relatives of people with mild intellectual disabilities } \\
\hline No & \multicolumn{2}{|c|}{$\begin{array}{l}\text { Relationship } \\
\text { to person with } \\
\text { intellectual } \\
\text { disabilities }\end{array}$} & $\begin{array}{l}\text { Age of } \\
\text { person with } \\
\text { intellectual } \\
\text { disabilities }\end{array}$ & $\begin{array}{l}\text { Sex of } \\
\text { person with } \\
\text { intellectual } \\
\text { disabilities }\end{array}$ \\
\hline 1 & \multicolumn{2}{|c|}{$\begin{array}{l}\text { Parents (double } \\
\text { interview) }\end{array}$} & 27 & Male \\
\hline 2 & \multicolumn{2}{|c|}{ Sister } & 57 & Male \\
\hline 3 & \multicolumn{2}{|c|}{ Mother } & 25 & Female \\
\hline 4 & \multicolumn{2}{|c|}{ Mother } & 27 & Female \\
\hline
\end{tabular}

